$\mathbf{R}_{\text {ESEARCh }} \mathbf{P}_{\text {Afer }} \longrightarrow$ FOOD SCIENCE

e ISSN-2230-9403 $\mathbf{\square}$ Visit us :
www.researchjournal.co.in

Volume 8 | Issue 1 | April, 2017 | 91-99

DOI : 10.15740/HAS/FSRJ/8.1/91-99

\title{
The distribution and characterization of Staphylococci in infant foods
}

\author{
Monika Sharma and Yogendra Kumar
}

Food poisoning microbial agent can cause diarrhoel disease and ill-health in infant. Staphylococcal organisms constitute a very important group of pathogens which is the great significance because these are the most common bacteria causing food poisoning. Being Iquitos in nature, staphylococci are usually present in raw milk and some strains may turn out to be exterotoxigonic S.aureus. The current investigation revealed significance variations in the staphylococcal counts of infant food. A total eight brands of infant milk food and three brands of weaning food samples were collected around from Meerut city in U.P. in the year 2009-10. The collected samples were analysed for staphylococcal counts and their characterization. Staphylococci were recovered from almost all brands of infant foods. Among positive samples, approximately, 3.28 per cent contained more than 5000 staphylococci per gram, while, 11.47 per cent had a count between 501 and 5000 and further observed that 26.23 per cent were considered to be of good quality as they contained less than 10 staphylococci per gram of samples. During the present study, 142 isolates of staphylococci were recovered from infant food samples. All these isolates produced catalase and fermented glucose anaerobically based on additional characters of production of coagulase, phosphatase and anaerobic fermentation of mannitol, 53 strains were identified as S.aureus. Therefore, there is a likelihood of incidence of these organisims in the finished products. The chance contamination during processing cannot also be ignored, because these are the most common bacteria causing food poisoning.

Key Words : Food poisoning, Infant food, Staphylococcal, Weaning food, Diarrhoel, Diseases

How to cite this article : Sharma, Monika and Kumar, Yogendra (2017). The distribution and characterization of Staphylococci in infant foods. Food Sci. Res. J., 8(1): 91-99, DOI : 10.15740/HAS/FSRJ/8.1/91-99. 